\title{
Assessment of indoor residual spraying and entomological collections of mosquitoes at the student village of Nasarawa State University Keffi, Nasarawa State, Nigeria
}

\author{
Hassan, S C. ${ }^{1}$, Lazarus, M. S. ${ }^{1}$, Eke, S. S. ${ }^{\star}$, Luka, J. ${ }^{1}$, Michael, O. D. ${ }^{1}$, \\ Peters, E. ${ }^{1}$ and Otuu, A. C. ${ }^{2}$ \\ ${ }^{1}$ Department of Zoology, Nasarawa State University, Keffi, Nigeria. \\ 2Department of Animal Biology, Federal University of Technology, Minna, Niger State, Nigeria. \\ *Corresponding author Email: ekesamuel2012@gmail.com
}

Copyright @ 2017 Hassan et al. This article remains permanently open access under the terms of the Creative Commons Attribution License 4.0, which permits unrestricted use, distribution, and reproduction in any medium, provided the original work is properly cited.

Received 10th January, 2018; Accepted 7th May, 2018

\begin{abstract}
Mosquitoes are found around our surroundings as they cause public disturbances whether harmful or beneficial. Mosquitoes are insect vectors which transmit many dreadful diseases causing serious health problems to human being. In this study, two sampling sites were selected, mud and concrete houses. Indoor mosquitoes were collected with the use of knock-down pyrethrum insecticide and morphological identification was done in the Insectary laboratory with the aid of a dissecting microscope, using standard procedures. A total of 748 adult mosquitoes were caught, out of which a higher number of $400(53.48 \%)$ mosquitoes were caught in mud houses while $348(46.52 \%)$ were caught in concrete houses. Higher numbers of Culex sp were recorded in both mud houses and concrete houses. 345(51.96\%) of the 400 mosquitoes from the mud houses were Culex sp while 55(65.48\%) were Anopheles sp. Out of the 348 mosquitoes caught in the concrete houses, 319(48.04\%) were Culex sp while 29(34.52\%) were Anopheles. A highest number, $278(37.17 \%)$, of mosquitoes were caught in the month of July while the least number, $234(31.28 \%)$, was recorded in the month of June. Statistically, there was a significant difference between the relative abundance and distribution of mosquitoes based on months $(P<0.05)$. The result of this study indicates the level of pollution in the area since Cullicines breed significantly in dirty stagnant water and due to the lack of proper drainage and sewage system in the study area. This can pose a serious health threat to the inhabitant. Health education will go a long way in sensitizing the inhabitants of the study area to avoid dumping of refuse indiscriminately.
\end{abstract}

Keywords: Concrete houses, Cullicines, insect vector, insectary, mud houses.

\section{INTRODUCTION}

Mosquitoes have through human history constituted a problem to man and animals. About 60 different genera of mosquitoes are found worldwide (defoliart, 2002). Of these genera, members of the Anopheles, Culex, Aedes, Hemagogus and Mansonia complexes are important pests in Nigeria (Oyewole et al., 2007). Mosquitoes not only inflict biting pains on man but also suck human blood and transmit disease pathogens and die soon after mating. The female mosquito bites humans and animals because they need blood for the development of eggs. The males are short-lived, do not suck blood but nectars and plant juices, and die soon after mating. The haematophagous habit of the female mosquitoes is of public health importance. Various parasitic and viral diseases are transmitted through the biting mosquitoes. Wuchereria bancrofti and Brugia malayi which cause lymphatic Filariasis in humans 
(WHO, 2010) are transmitted by members of the Aedes, Culex and Mansonia complexes. Yellow fever and Dengue viruses are equally transmitted by these mosquitoes (Onyibo et al., 2002). The need to control mosquitoes becomes paramount when its threats to public health are considered. In the developed parts of the World, organized Mosquito control strategies are carried out by various agencies supported by the Government. Their efforts are channeled towards water management, biological control agents and the use of insecticides in controlling the larvae and adults. Apart from organized approaches, Pedigo and Rice (2009) posited that residents can help significantly by controlling mosquitoes around their houses. The extensive use of chemicals to control mosquito populations and reduce the burden of disease has led to the widespread emergence and spread of insecticide-resistance (Sogoba et al., 2007). Insecticide resistance counters control methods by increasing vector population sizes above the critical thresholds required for disease management. Aside from its effect on vector numbers, however, insecticide resistance may also alter the quality of mosquitoes as vectors of disease (White et al., 2011; Smith, 2004). In other words, insecticide resistant mosquitoes may be better (or worse) vectors of diseases than susceptible ones, a possibility which, if confirmed, could have drastic epidemiological and public health consequences (Sogoba et al., 2007).Out of the four classes of insecticides (organochlorine, pyrethroids and carbamates and organophosphates) approved for malaria vector control (Oyewole et al., 2005), pyrethroids are the commonest insecticides used for IRS and the only insecticide class recommended for use in ITNs (WHO, 2010). This is for safety, efficacy, acceptability and cost reasons (WHO, 2010). Unfortunately, resistance to pyrethroids in An. gambiae s.l and An. funestus has emerged and it is spreading rapidly (Adebanjo et al., 2012; Snow et al., 2005). This has constituted an impediment to vector control initiatives in African countries (WHO, 2005). In Nigeria, the development of resistance to DDT and other classes of insecticides including organochlorine, organophosphate, carbamates and recently pyrethroid has been reported in Anopheles gambiae s.s., Anopheles arabiensis and Anopheles funestus from different zones (Awolola et al., 2005, 2007). In south-west Nigeria, the first case of pyrethroid resistance in Anopheles gambiae, the major malaria vector, in Nigeria was documented (Awolola et al., 2002) and since then the phenomenon has been well established in this region (Awolola et al., 2003; Santolamazza et al., 2008; Awolola et al., 2005, 2007; Oduola et al., 2012). Also in North-central Nigeria, Permethrin and DDT resistance in An. gambiae s.l has been reported (Lamidi, 2009; Olayemi et al., 2011).

The main aim of this work is to have a baseline entomological assessment of malaria vectors, Anopheline mosquitoes through indoor residual pyrethrum spray collection (PSC) method using hostels in Nasarawa state university campus.

\section{MATERIALS AND METHODS}

\section{Study area}

Nasarawa State University is in Keffi Local Government Area of Nasarawa state, North Central, Nigeria (Figure 1). The town is $68 \mathrm{~km}$ from Abuja, the Nation's Federal Capital Territory and $128 \mathrm{Km}$ from Lafia, the Nasarawa State capital. Keffi is located between Latitude $8^{\circ} 50^{\prime} 47^{\prime \prime} \mathrm{N}$ and Longitude $7^{\circ} 52^{\prime 2} 24^{\prime \prime} \mathrm{E}$ with elevation of $321 \mathrm{~m}$ above sea level (https://en.wikipedia.org/wiki/Keffi). According to the 2006 National Census, Keffi has an estimated population of 92,664 in which more than $60 \%$ reside in the rural areas (https://en.wikipedia.org/wiki/Keffi). From North to South of Keffi, runs the River Antau that provides water for drinking, washing and the outlet of some marshy places for rice farming. Keffi also experience a raining season that lasts from April to October and a dry season from November to March. Temperatures are generally high during the day, particularly between the months of March and April. The mean monthly temperatures in the state range between $20^{\circ} \mathrm{C}$ and $34^{\circ} \mathrm{C}$, with the hottest months being March/April and the coolest months being December/January. The major part of the soil Loamy soils. Vegetation falls within the southern guinea savanna zone. The majorities of the rural people are engaged in agriculture and are known to be sparsely settlement in the countryside.

\section{Experimental design}

Preliminary assessments to identify and map out the sampling sites in these areas weremade. Selection and categorization of sampling sites were based on human activities involved. Two hostels sites were selected for this research. In these sites indoor mosquitoes were collected. The indoor mosquitoes were collected by the use of knock down pyrethoid (aerosols) insecticides and identification was done with the aid of monographs and dissecting microscopes (Gillies and Coetzee, 1987).

\section{Sampling collection}

Mosquitoes were collected by pyrethium spray collection method. Indoor Mosquitoes were collected from rooms by PSC method using Baygon insecticides containing 0.05\% imiprothrin, $0.05 \%$ prallethrin and $0.015 \%$ cyfluthrin. Collection was done from 6 to 8:00 am between the month of March and May, 2016.

\section{Collection of indoor mosquitoes using aerosol insecticide}

Pyrethrum spray collection (PSC) method as described by WHO, (1980) was used to sample indoor resting 


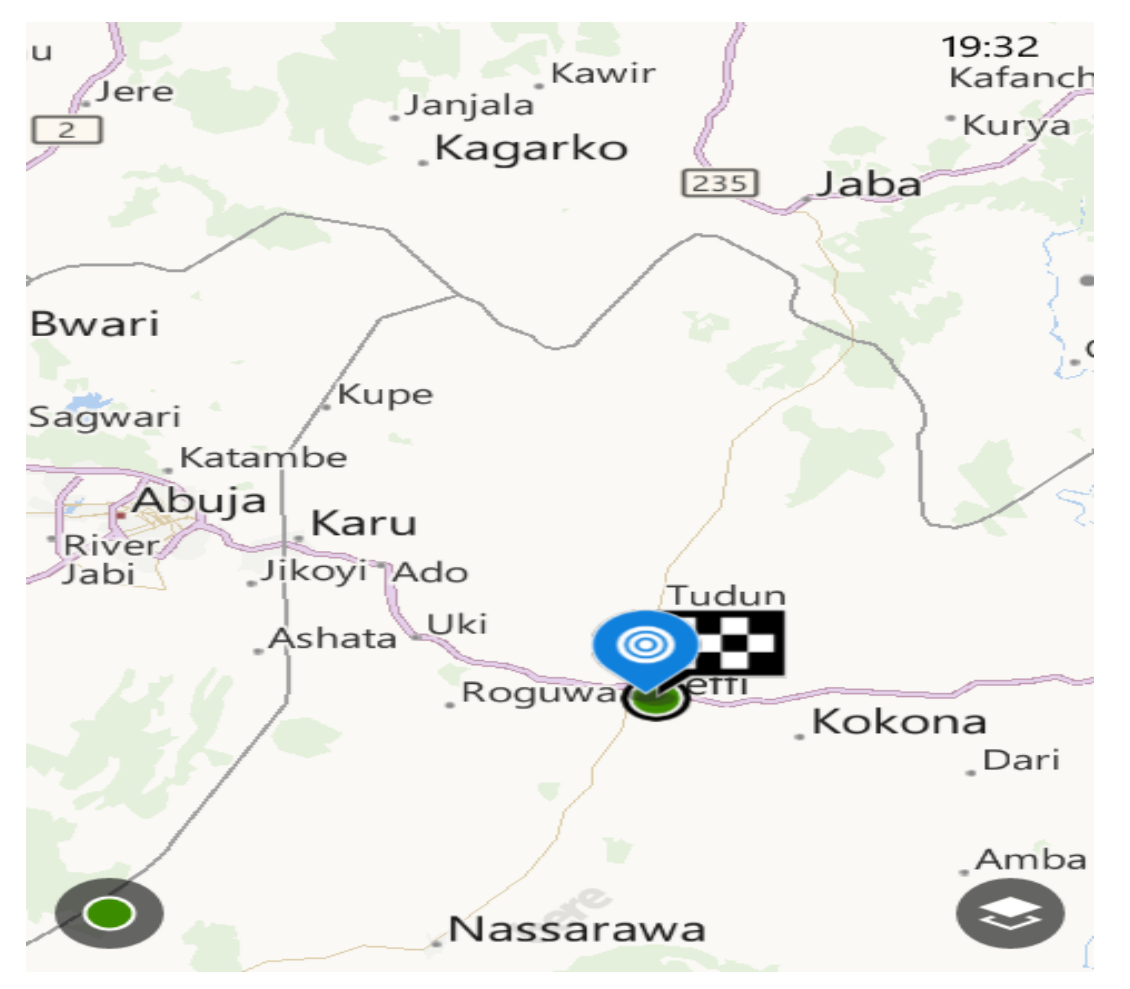

Figure 1. Keffi on Google map.

mosquitoes for the baseline data. A room occupied by individuals the previous night was used for the collection, pyrethrum spray collection method was used and collection of mosquitoes was made in the morning before $8 \mathrm{am}$. Prior to spraying, all individuals occupying the room were evacuated, all food covered and small furniture was removed from the room. White sheet was then laid to completely cover the floor and also ensuring that the sheet is spread under the tables. All windows and doors were closed. The targeted room was sprayed from outside with pyrethrum-based Baygon insecticide through the openings below doors and later inside (clockwise) on ceiling and walls until the room was filled with the insecticidal mist. After 10 minutes the room was opened and the sheet was carefully picked up at the corners by about five individuals and the mosquitoes were hand-picked with a featherweight forceps in to a petri dish.

\section{Mosquito preservation and labeling}

All knockdown mosquitoes were collected in day-light with forcep and preserved in an Eppendorf tube containing silica-gel with the collection date, study site name clearly labelled on the tube. The mosquitoes were put in the tube in order to keep the delicate body parts of the mosquitoes such as palp, antenna, wings and legs which are of significant importance in identification. In the laboratory, mosquitoes collected were identified to species using the key guide of Gillies and Coetzee (1987) morphologically.

\section{Statistical analysis}

The data generated were analyzed using the relative frequencies and mean values of the records. Charts were also used to express some of the observations. The relative abundance and distribution of the mosquitoes and species were determined and expressed as percentages of the total. One Way Analysis of Variance (ANOVA) was further used in the data analysis and means were separated using the critical difference (LSD) values.

\section{RESULTS}

The results of the mosquito species found in both mud/concrete houses of Nasarawa State University and environs are shown in Tables 1 to 4 . Table 1 showed the total number of mosquito collected and percentage abundance in mud and concrete houses.

\section{The total number collected and percentage abundance of mosquito caught in mud and concrete house}

A total of 748 adult mosquitoes were collected, the highest number of $400(53.48 \%)$ were caught in mud houses while $348(46.52 \%)$ were caught in concrete houses (Table1). Higher numbers of Culex sp. were recorded in both mud houses and concrete houses. 345 (86.25\%) of the 400 mosquitoes from the mud houses were Culex $s p$. while 55 
Table 1. The total number collected and percentage abundance of mosquito caught in mud and concrete house.

\begin{tabular}{lccc}
\hline Locations & No. Collected (\%) & No. of Anopheles (\%) & No. of Culex (\%) \\
\hline Mud House & $400(53.48)$ & $55(13.75)$ & $345(86.25)$ \\
Concrete House & $348(46.52)$ & $29(8.33)$ & $319(91.67)$ \\
Total & $748(100)$ & $84(11.23)$ & $664(88.77)$ \\
\hline
\end{tabular}

${ }^{* *}$ Correlation is highly significant at 0.01 level (2-tailed). The correlation test shows a high significance correlation between the mosquitoes caught in the mud and concrete houses in the study area.

Table 2. Relative abundance of adult mosquitoes collected from the month of May to July 2016.

\begin{tabular}{lccccc}
\hline \multirow{2}{*}{ Date } & \multicolumn{2}{c}{ Mud House } & \multicolumn{2}{c}{ Concrete House } & \multirow{2}{*}{ Total (\%) } \\
\cline { 2 - 5 } & Anopheles & Culex & Anopheles & culex & \\
\hline May & 23 & 128 & 5 & 80 & $236(31.55)$ \\
June & 25 & 77 & 14 & 118 & $234(31.28)$ \\
July & 7 & 140 & 10 & 121 & $278(37.17)$ \\
Total & 55 & 345 & 29 & 319 & 748 \\
\hline
\end{tabular}

$\mathrm{Fcal}=21.42 ; \mathrm{F}$ critical $=4.07 ; \mathrm{df}=3,8$ at $\mathrm{P}<0.05$ (There is a significant difference) on the relative abundance of the mosquito vectors found in both types of houses i.e the mud and the concrete houses in the study area.

(13.75\%) were Anopheles sp. Out of the 348 mosquitoes caught in the concrete houses, $319(91.67 \%)$ were Culex sp while 29 (8.33\%) were Anopheles as shown in Table 1. One-way analysis of variance showed that there is a significance difference between the prevalence of mosquitoes in both mud and concrete houses $(P<0.05)$.

All the mosquitoes encountered belonged to two orders; Anophelinae and Culicidae. The most predominant genus was Culex with a total of $664(88.77 \%)$ adult mosquitoes while Anophelines made up the remaining $11.23 \%$ with a total of 84 adult mosquitoes. The Anophelines were represented by the genus Anopheles while the Culicines were represented by the genus Culex. The distribution of mosquitoes in the various months showed $278(37.17 \%)$ is the highest number of mosquitoes which occurred in the month of July, followed by the month of May with 236 $(31.55 \%)$ while the lowest was recorded in the month of June with $234(31.28 \%)$ as shown in Table 2. One-way analysis of variance shows that there is a significance difference between the relative abundance and distribution of mosquitoes between the months of July and others $(\mathrm{P}<0.05)$.

The results of the collection of mosquitoes and examination of the stages of blood digestion are shown in Tables 3 and 4 . The gravid and/or semi gravid appearance of the abdomen demonstrate as resting stages, while the mosquitoes with unfed stomach/abdomen with or freshly fed are indicative of the feeding stage of the vector.

Table 3 showed the number of Anopheles and Culex collected in mud houses, their abdominal conditions and their percentage prevalence for the three months of study. A total of 400 mosquitoes were collected from mud houses of which the highest number examined was 151 which was collected in the month of May followed by the month of July with 147 while the lowest was recorded in June with 102 mosquitoes. From the Table 3 , it can be deduced that the Anopheles with fed abdominals were the highest 155 $(38.75 \%)$ observed during these three months of study followed by unfed $136(34.0 \%)$ and the lowest recorded was gravid with 50 (12.5\%). Analysis of variance showed significant difference in the months of collections and in the abdominal conditions $(p<0.05)$ (Table 3$)$.

Table 4 showed the number of Anopheles and Culex collected in concrete houses, their abdominal conditions and their percentage prevalence for the three months of study. A total of 348 mosquitoes were collected from concrete houses of which the highest number examined 132 were collected in the month of June followed by the month of July with 131 while the lowest was recorded in May with 85 mosquitoes. From the Table 4, it can be deduced that the mosquitoes with unfed abdominals constituted the highest number, 170 (48.85\%), observed during these three months of study followed by fed, 104 $(29.89 \%)$, and the lowest recorded was half gravid with 33 $(9.48 \%)$ each. Analysis of variance shows significance difference in the months of collections and in the abdominal conditions $(p<0.05)$ (Table 4).

\section{DISCUSSION}

Mosquito occurrence in various habitats has been investigated by different researchers including Ayanda (2009) who studied the relative abundance and distribution of malaria vectors in Ugah, Nasarawa State, Nigeria. Hay et al. (2000) stated that the occurrence and relative 
Table 3. Nnumber of Anopheles and Culex collected in Mud houses, their abdominal conditions and their percentage prevalence for the three months of study.

\begin{tabular}{llllcccc}
\hline Months & Species & Unfed & Fed & Gravid & Half gravid & Total & No. of occupant \\
\hline May & Anopheles & 07 & 11 & 03 & 02 & 23 & 04 \\
& Culex & 37 & 44 & 20 & 27 & 128 & 03 \\
\multirow{3}{*}{ June } & Anopheles & 13 & 02 & 07 & 03 & 25 & 03 \\
& Culex & 07 & 44 & 09 & 17 & 77 & 03 \\
\multirow{4}{*}{ July } & Anopheles & 01 & 05 & 00 & 01 & 07 & 03 \\
& Culex & 71 & 49 & 11 & 09 & 140 & 03 \\
Total & & $136(34.0 \%)$ & $155(38.75 \%)$ & $50(12.5 \%)$ & $59(14.75 \%)$ & $400(100 \%)$ & 19 \\
\hline
\end{tabular}

$\mathrm{Fcal}=1.39 ; \mathrm{F}$ critical $=3.10 ; \mathrm{df}=3.20$ at $\mathrm{P}>0.05$ (There is no significant difference).

Table 4. The number of Anopheles and Culex collected in Concrete houses, their abdominal conditions and their percentage prevalence for the three months of study.

\begin{tabular}{lllccccc}
\hline Months & Species & Unfed & Fed & Gravid & Half gravid & Total & No. of occupants \\
\hline May & Anopheles & 01 & 02 & 02 & 00 & 05 & 02 \\
& Culex & 39 & 26 & 11 & 04 & 80 & 03 \\
\multirow{2}{*}{ June } & Anopheles & 06 & 08 & 00 & 00 & 14 & 03 \\
& Culex & 52 & 13 & 26 & 27 & 118 & 03 \\
\multirow{4}{*}{ July } & Anopheles & 70 & 49 & 01 & 01 & 121 & 02 \\
& Culex & 02 & 06 & 01 & 01 & 10 & 02 \\
Total & & $170(48.85 \%)$ & $104(29.89 \%)$ & $41(11.78 \%)$ & $33(9.48 \%)$ & $348(100 \%)$ & 07 \\
\hline
\end{tabular}

Fcal $=1.94 ; \mathrm{F}$ critical $=3.10 ; \mathrm{df}=3,20$ at $\mathrm{P}>0.05$ (There is no significant difference) base on the stomach stage digestion of blood for both concrete and the mud houses for the period of three months.

abundance of mosquito distribution in different habitats reflect the egg-laying preference of females Anopheles vector as well as the ability of the immature mosquito to survive under the prevailing conditions. It has also been established that the underground portions of the drainage systems with stable microclimatic conditions offer ideal habitats for breeding of larvae and resting of adults of domestic and peri- domestic mosquitoes (Hodges et al., 2013; Kacey et al., 2006).

Out of the two types of houses surveyed, a total of 748 adult mosquitoes were collected, the highest number of $400(53.48 \%)$ were caught in mud houses while 348 $(46.52 \%)$ were caught in concrete House as shown in (Table 1). One-way analysis of variance shows that there was a significance difference between the prevalence of mosquitoes in both houses $(p<0.05)$. This prevalence might be due to unhygienic practices in these houses. Only adult mosquito of Anopheles and Culex were collected. This is in line with the observation made by Onyido et al. (2002) on the co-existence of these two species in a particular site or area. The most predominant genus was Culex with a total of $664(88.77 \%)$ adult mosquitoes while the remaining mosquitoes collected were Anopheles. The low population of the Anopheles mosquitoes could be attributed to the period of this study May to July and this is in agreement with observation made by Killeen et al. (2000) who stated that, population of Anopheles mosquitoes increases with increase in rainfall with the peak season around August to September. MartinezTorres (1998) and Kent and Norris (2005) recorded extremely high Culex population in wastewater treatment ponds in Florida. Similarly, Okogun et al. (2003) reported very high Culex population in untreated wastewater and at a later stage of wastewater treatment.

A highest number of 151 mosquitoes were collected in the month of May, followed by 147 in the month of July, and the lowest number of 102 mosquitoes in June. Conclusively, the highest number of mosquitoes was collected in May and July respectively. The results showed that mosquito abundance was directly related to rainfall. This study is line with the principle that mosquito abundance has a positive relationship with rainfall and inversely related to temperature which also agrees with the findings in the Imo River Basin of Nigeria by Uttah et al. (2013). Though some studies in Abeokuta, South west Nigeria showed that mosquito abundance increased as the season progressed from January with a drastic decline between June and July (Adeleke et al., 2010; Minakawa et 
al., 2004). The indiscriminate preference of all houses by this species of mosquitoes supports the findings of Okorie (2011), in which mosquito was found in all the microhabitats.

Mosquitoes of the genus Anopheles are primary malaria vector worldwide. In Nigeria, the most common are Anopheles gambiae complex. This species carries the parasite Plasmodium falciparum which causes malaria and has also been associated with the transmission of filariasis (Okon et al., 2010; Okwa et al., 2006). The mosquito species identified in this study are of public health importance, there is need to sanitize and clean up these houses. This will not only get rid of these species of breeding sites but also free the State of the diseases associated with these organisms.

\section{Conclusion}

A total of 748 adult mosquitoes were collected, the highest number of 400 (53.48\%) were caught in mud houses while $348(46.52 \%)$ were caught in concrete house. All the mosquitoes encountered belong to two genera, Anophelinae and Culicidae. The most predominant genus was Culex with a total of $664(88.77 \%)$ adult mosquitoes while Anopheline was the remaining $11.23 \%$ with a total of 84 adult mosquitoes, the lack of good drainage and sewage systems in the study area could be some of the factors contributing to the higher number of mosquitoes recorded. In addition, the studies further indicated that mosquitoes are more adapted to the mud houses than the concrete houses probably due to the texture and the nature of the constructed houses.

\section{CONFLICT OF INTEREST}

The authors declare that they have no conflict of interest.

\section{REFERENCES}

Adebanjo, F., Oni, M. O. \& Moro, D. D. (2012). Basic entomology course guide. Published by National Open University of Nigeria, 1.

Awolola, S. T., Ibrahim, K., Okorie, T., Koekemoer, L. L., Hunt, R. H., \& Coetzee, M. (2003). Species composition and biting activities of anthropophagic Anopheles mosquitoes and their role in malaria transmission in a holo-endemic area of south western Nigeria. African Entomology, 11, 227- 232.

Awolola, T. S., Oduola, A. O., Obansa, J. B., Chukwurar, N. J., \& Unyimadu, J. P. (2007). Anopheles gambiae s.s. breeding in polluted water bodies in urban Lagos, South western Nigeria. Journal of Vector Borne Diseases, 44, 241-244.

Awolola, T. S., Okwa, O., Hunt, R. H., Ogunrinade, A. F., \& Coetzee, M. (2002). Dynamics of the malaria-vector populations in coastal Lagos, south western Nigeria. Annals of Tropical Medicine and Parasitology, 96(1), 75-82.

Awolola, T. S., Oyewole, I. O., Koekemoer, L. L. \& Coetzee, M.
(2005). Identification of three members of the An. funestus group and their role in transmission in two ecological zones of Nigeria. Transactions of the Royal Society of Tropical Medicine and Hygiene, 99(7), 25-531.

DeFoliart, G. R. (2002). The Human Use of Insects as a Food Resource: A Bibliographic Account in Progress. Retrieved from http://www.food-insects.com/book. Accessed January 25, 2013.

Gillies, M. T., \& Coetzee, M. (1987). A supplement to the Anophelinae of Africa South of the Sahara (Afrotropical Region). Publications of the South African Institute for Medical Research, No. 55.

Hay, S. I., Rogers, D. J., Toomer, J. F., \& Snow, R. W. (2000). Annual Plasmodium falciparum entomological inoculation rates (EIR) across Africa: literature survey, Internet access and review. Transactions of the Royal Society of Tropical Medicine and Hygiene, 94, 113-127.

Hodges, T. K., Athrey, G., Deitz, K. C., Overgaard, H. J., Matias, A., Caccone, A., \& Slotman, M. A. (2013). Large fluctuations in the effective population size of the malaria mosquito Anopheles gambiae ss during vector control cycle. Evolutionary applications, 6(8), 1171-1183.

Kacey, E. C., Samson, A. O., Dickens, K. O., Mark, W. L., \& Chandy, J. C. (2006). Malaria hotspot areas in a highland Kenya site are consistent in epidemic and non-epidemic years and are associated with ecological factors. Malaria Journal, 5, 78-82.

Kent, R. J., \& Norris, D. E. (2005). Identification of mammalian blood meals in mosquitoes by a multiplexed polymerase chain reaction targeting cytochrome B. Amsterdam Journal of Tropical Medicine and Hygiene, 73, 336-342.

Killeen, G., Fillinger, U., Kiche, I., Gouagna, L. C., \& Knola, B.G (2002). An eradication of Anopheles gambiae from Brazil: Lessons for malaria control in Africa. Lancet Infectious Disease, 2, 618-627.

Lamidi, T. B. (2009). Distribution and seasonal abundance of anopheline mosquito species in Nguru, Yobe State, NorthEastern Nigeria. Animal Research International, 6(1), 949-952.

Martinez-Torres, D. (1998). Molecular characterization of pyrethroid knockdown resistance (kdr) in the major malaria vector Anopheles gambiae s.s. Insect Molecular Biology, 7, 179-184.

Minakawa, S. N. G., Mogi, M., \& Yan, G. (2004). Habitat characterization of Anopheles gambiae s.s. Iarvae in a Kenyan highland. Medical Veterinary Entomology, 18, 301-305.

Oduola, A. O., Otunbanjo, O. A., Olojede, J. B., Oyewole, I. O., \& Awolola, T. S. (2012). Malaria transmission risk indices of three Anopheles species in selected rural communities in Oyo State South-Western Nigeria. International Journal of Tropical Medicine, 7(1), 42-48.

Okogun, G. R. A., Nwoke, B. E. B., Okere, J. C., \& Anegbe, C. (2003). Epidemiological Implications of Preferences of Breeding Sites of Mosquito Species in Midwestern Nigeria. Annals of Agricultural and Environmental Medicine, 10, 217222.

Okon, O. E., Iboh, C. I., \& Opara, K. N. (2010). Bancroftian filariasis among the Mbembe people of Cross River State, Nigeria. Journal of Vector Borne Disease, 47(2), 91-96.

Okorie, P. N., McKenzie, F. E., Ademowo, O. G., Bockarie, M., \& Kelly-Hope, L. (2011). Nigeria Anopheles vector database: an overview of 100 year's research. 6 , e28347.

Okwa, O. O., Carter, V., \& Hurd, H. (2006). Abundances, host preferences and infectivity rates of malaria vectors in Badagry Local government area of Lagos, Nigeria. Journal of 
Parasitology, 27, 41-48.

Olayemi, I. K., Ande, A. T., Ayanwale, A. V, Mohammed, A. Z., Bello, I. M., Idris, B, Isah, B., Chukwuemeka, V., \& Ukubuiwe, A. C. (2011). Seasonal trends in epidemiological and entomological profiles of malaria transmission in North Central Nigeria. Pakistan Journal of Biological Sciences, 14(4), 293299.

Onyido, A. E., Ikpo, A. U., Obiukwu, M. O., \& Amadi, E. S. (2012). Vector abundance and prevalence of malaria parasites among hostel residential students of Nnamdi Azikiwe University Awka, Southeastern Nigeria. Nature and Science, 10(11), 150-155.

Oyewole, I. O., Awolola, T. S., Ibidabo, C. A., Oduola, A. O., Okwa, O. O., \& Obansa, J. A. (2007). Behaviour and population dynamics of major anopheline vectors in a malaria endemic area in southern Nigeria. Journal of Vector Borne Disease, 44, 56-64.

Oyewole, I. O., Ibidapo, A. C., Oduola, A. O., Obansa, J. B., \& Awolola, S. T. (2005). Molecular identification and population dynamics of the major malaria vectors in a rainforest zone of Nigeria. Biokemistri, 17(2), 171-178.

Pedigo, L. P., \& Rice, M. E. (2009). Entomology and Pest Management. Prince-Hill, London. p. 601.

Santolamazza, F., Mancini, E., Simard, F., Qi, Y., Tu, Z., \& della Torre, A. (2008). Structure and insertion polymorphisms of SINE200 retrotransposons in genomic islands of speciation of Anopheles gambiae molecular forms. Malaria Journal, 7, 163.

Smith, T., Killeen, G., Lengeler, C., \& Tanner, M. (2004). Relationships between the outcome of Plasmodium falciparum infection and the intensity of transmission in Africa. Amsterdam Journal of Tropical Medicine and Hygiene, 71, 80-86.

Snow, R., Hay, S. I., Cox, J., Roggers, D. J., Randolph, S. E., Stern, D. I., Shanks, G. D. \& Myers, M. F. (2005). The global distribution of clinical episodes of Plasmodium falciparum malaria. Nature, 434, 214-217.
Sogoba, N., Doumbia, S., Vounatsou, P., Baber, I., Keita, M., Maiga, M., Traore, S. F., Toure, A. Dolo, G., Smith, T., \& Ribeiro, J. M. C. (2007). Monitoring of Larval Habitats and Mosquito Densities in the Sudden Savannah of Mali: Implication for Malaria Vector Control. American Journal of Tropical Medicine and Hygiene, 77(1), 82-88.

Uttah, E. C., Iboh, C. I., Ajang, R., Osim, S. E., \& Etta, H. (2013). Physiological age composition of female anopheline mosquitoes in an area endemic for malaria and filariasis. International Journal of Scientific and Research Publications. 3(7), 1-4.

White, M. T., Griffin, J. T., Churcher, T. S., Ferguson, N. M., Basanez, M. G., \& Gbani, A. C. (2011). Modelling the impact of vector control interventions on Anopheles gambiae population dynamics. Parasites and Vectors, 28, 4.

World Health Organization (1980). The Garki Project: research on the epidemiology and control of malaria in Sudan Savanna of West Africa by L. Molineaux and G. Gramiccia. Geneva, Switzerland.

World Health Organization (2005). Guidelines for laboratory and field testing of mosquito larvicides. WHO/CDS/WHOPES/GCDPP/2005.13.

World Health Organization (2010). World Malaria report, 2010. Malaria fact sheet No. 94. WHO, Geneva. 